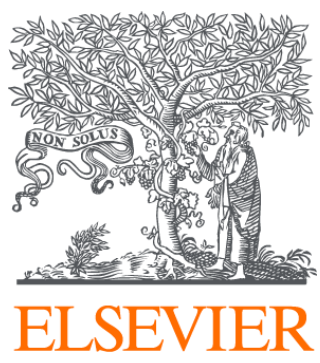

Since January 2020 Elsevier has created a COVID-19 resource centre with free information in English and Mandarin on the novel coronavirus COVID-

19. The COVID-19 resource centre is hosted on Elsevier Connect, the company's public news and information website.

Elsevier hereby grants permission to make all its COVID-19-related research that is available on the COVID-19 resource centre - including this research content - immediately available in PubMed Central and other publicly funded repositories, such as the WHO COVID database with rights for unrestricted research re-use and analyses in any form or by any means with acknowledgement of the original source. These permissions are granted for free by Elsevier for as long as the COVID-19 resource centre remains active. 


\section{Climate change and COVID-19: reinforcing Indigenous food systems}

Indigenous populations are at especially high risk from COVID-19 because of factors such discrimination, social exclusion, land dispossession, and a high prevalence of forms of malnutrition. ${ }^{1}$ Climate change is compounding many of these causes of health inequities, undermining coping mechanisms that are traditionally used to manage extreme events such as pandemics, and disrupting food systems and local diets. ${ }^{2}$ Addressing underlying structural inequities and strengthening Indigenous knowledge systems offer opportunities for building resilience to compound socioecological shocks, including climate effects and pandemics.

Climate change is affecting Indigenous food systems, making Indigenous populations vulnerable to food and nutritional insecurity. ${ }^{3}$ The nature and extent of the effects of COVID-19 on Indigenous food systems are still largely unknown, but the direct results include mortality from severe illness, reduced access to food, changes in local diet, and economic losses resulting from lockdowns. These outcomes present impediments to the recovery of populations already facing substantial nutritional challenges. The effects of previous pandemics on Indigenous food systems affected children in particular, when adults became ill and household food access was reduced. ${ }^{4}$ Inadequate health service provision for Indigenous populations, including scant access to culturally safe services, ${ }^{5}$ adds another layer of complexity in the face of the COVID-19 pandemic. Effects of climate change undermine Indigenous food security, in turn compromising the resilience of Indigenous populations to pandemics. At the same time, disruptions to food and nutrition security and the resulting health implications for Indigenous populations during pandemics exacerbate their vulnerability to climate change. In this context, understanding, reinforcing, and protecting Indigenous food systems in the context of a changing climate must be a cornerstone of post-pandemic recovery.

In the Peruvian Amazon, some Shawi Indigenous communities have chosen to self-isolate in the forest during the COVID-19 pandemic. ${ }^{6}$ These communities are relying on traditional diets and Indigenous knowledge of local food systems, and they have little availability and accessibility to external food and government food-aid programmes. During this self-isolation, reliance on Indigenous food systems is inextricably linked to Indigenous knowledge about the land, rivers, and biodiversity, which includes knowledge of local techniques to preserve and prepare food? However, food from the forest is being affected by biodiversity and vegetation loss: heatwaves, precipitation variation, and more frequent and intense extreme weather events are all related to deforestation and climate change and are compounded by a weakening of traditional hunting and fishing skills as a result of climatic and societal changes. ${ }^{6,8,9}$ In the Arctic, Inuit are witnessing some of the most rapid rates of warming globally. ${ }^{3}$ The remoteness of the region and travel restrictions have helped curtail the spread of COVID-19; however, disruptions to supply networks have had effects on food availability in communities that rely on retail food flown in from southern regions. To manage these disruptions, harvesting and sharing local foods, which is widely practiced in many Arctic regions ${ }^{9}$ has helped maintain food and nutrition security. Simultaneously, however, these local Indigenous food systems have been compromised by climatic extremes, including record-breaking temperatures, drought, and wildfires.

In Uganda, some Indigenous populations (eg, Batwa) have adhered to COVID-19 measures, including physical distancing, staying home, and avoiding trading centres because of crowds, which challenge food and nutrition security by restricting access to markets. Furthermore, timely government food aid has not adequately reached Indigenous populations. The extended lockdown in Uganda, particularly for border districts where many Indigenous populations live, has hampered their mobility to access forested areas for foraging, access to nearby communities to offer labour for food exchange, and access to agricultural fields for food production. These challenges are exacerbated by existing climate effects, ${ }^{9}$ including recent flooding in 2019 that damaged crops, compromised food production, ${ }^{10}$ and reduced the resilience of Indigenous populations when the COVID-19 pandemic hit.

Climate change challenges the resilience of Indigenous food systems with direct and immediate repercussions

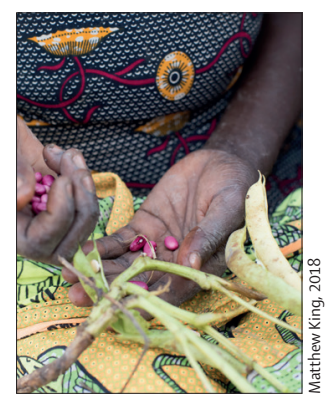

Published Online August 7, 2020 https://doi.org/10.1016/ S2542-5196(20)30173-X This online publication has been corrected. The corrected version first appeared at thelancet.com/planetaryhealth on September 9, 2020 
for the health and nutrition of Indigenous populations. ${ }^{2}$ In our highly connected world, the COVID-19 pandemic has easily travelled across continents, reaching remote geographical locations and Indigenous communities in less than 6 months. There is a vital window of opportunity to support Indigenous populations who face the double and syndemic burden of compound and cascading socioecological hazards, such as climate change and pandemics, by prioritising the protection of key Indigenous food sources (eg, tropical forests, Arctic ecosystems), by reinforcing and supporting the importance of Indigenous knowledge systems, by improving access to culturally safe health resources, and by and safeguarding access and rights to land and natural resources of Indigenous populations. This is the time to ensure that current decisions and development trajectories do not further jeopardise the resilience of Indigenous food systems, which have integral roles in the response of Indigenous populations to current and future pandemics and climatic changes.

We declare no competing interests. CZ-C was supported by the National Institute for Health Research (NIHR), using the UK's Official Development Assistance funding, and by Wellcome (218743/Z/19/Z) under the NIHR-Wellcome Partnership for Global Health Research. CZ-C is member of the Indigenous Health and Adaptation to Climate Change Research Group. IA-R, JDF, SL, PJG, DBN, MN, CJW, LB-F, and SLH are funded by the Canadian Institutes for Health Research through the Indigenous Health Adaptation to Climate Change programme. JJM acknowledges support from the Alliance for Health Policy and Systems Research (HQHSR1206660), the Bernard Lown Scholars in Cardiovascular Health Program at Harvard T H Chan School of Public Health (BLSCHP-1902), Bloomberg Philanthropies (via University of North Carolina at Chapel Hill School of Public Health), Fondecyt (National Fund for Scientific, Technological Development and Technological Innovation) via Cienciactiva at Concytec (Consejo Nacional de Ciencia Tecnología e Innovacíon Tecnologica), British Council, British Embassy and the Newton-Paulet Fund (223-2018, 224-2018), Department for International Development, Medical Research Council (MRC), and Wellcome Global Health Trials (MR/M007405/1), Fogarty International Center (R21TW009982, D71TW010877) Grand Challenges Canada (0335-04), International Development Research Center Canada (IDRC 106887, 108167), Inter-American Institute for Global Change Research (IAI CRN3036), MRC (MR/P008984/1, MR/P024408/1, MR/P02386X/1) National Cancer Institute (1P20CA217231), National Heart, Lung and Blood Institute (HHSN268200900033C, 5U01HL114180, 1UM1HL134590), National Institute of Mental Health (1U19MH098780), Swiss National Science Foundation (40P740-160366), Wellcome (074833/Z/04/Z, 093541/Z/10/Z, 103994/Z/14/Z 107435/Z/15/Z, 205177/Z/16/Z, 214185/Z/18/Z, 218743/Z/19/Z), and the World Diabetes Foundation (WDF15-1224). The views expressed are those of the authors and not necessarily those of Wellcome, the NIHR or the Department of Health and Social Care. The funding sources had no role in the preparation of this Comment or in the decision to submit for publication. We acknowledge the contribution of Matthew King
Copyright (c) 2020 The Author(s). Published by Elsevier Ltd. This is an Open Access article under the CC BY 4.0 license.

*Carol Zavaleta-Cortijo, James D Ford,

Ingrid Arotoma-Rojas, Shuaib Lwasa,

Guillermo Lancha-Rucoba, Patricia J García, J Jaime Miranda Didacus B Namanya, Mark New, Carlee J Wright,

Lea Berrang-Ford, the Indigenous Health Adaptation to

Climate Change Research Teamt, and Sherilee L Harper

carol.zavaleta.c@upch.pe

†Team members listed in the appendix

Universidad Peruana Cayetano Heredia, Urbanización Ingeniería, San Martín de Porres, Lima 31, Peru (CZ-C, PJG, JJM); Priestley International Centre for Climate, University of Leeds, Leeds, UK (JDF, IA-R, LB-F); Department of Geography, Geo-Informatics and Climatic Sciences, Makerere University, Kampala, Uganda (SL); Red de Salud Alto Mayo, Ministerio de Salud del Perú, San Martin, Peru (GL-R); Uganda Martyrs University, Kampala, Uganda (DBN); African Climate Development Initiative, University of Cape Town, Rondebosch, South Africa (MN); School of International Development, University of East Anglia, Norwich, UK (MN); and School of Public Health, University of Alberta, Edmonton, AB, Canada (CJW, SLH)

1 Anderson I, Robson B, Connolly M, et al. Indigenous and tribal peoples health (The Lancet-Lowitja Institute Global Collaboration): a population study. Lancet 2016; 388: 131-57.

2 Ford JD, King N, Galappaththi EK, Pearce T, McDowell G, Harper SL. The resilience of Indigenous Peoples to environmental change. One Earth 2020; 2: 532-43.

3 Intergovernmental Panel on Climate Change. Special report: global warming of $1.5^{\circ} \mathrm{C}$. 2018. https://www.ipcc.ch/sr15/ (accessed July 24, 2020).

4 Mamelund S-E, Sattenspiel L, Dimka J. Influenza-associated mortality during the 1918-1919 influenza pandemic in Alaska and Labrador: a comparison. Soc Sci Hist 2013; 37: 177-229.

5 Brascoupé S, Waters C. Cultural safety exploring the applicability of the concept of cultural safety to aboriginal health and community wellness. Int JIndigen Health 2006; 5: 6-41.

6 Zavaleta C. COVID-19: review Indigenous peoples' data. Nature 2020; 580: 185

7 Zavaleta C, Berrang-Ford L, et al. Multiple non-climatic drivers of food insecurity reinforce climate change maladaptation trajectories among Peruvian Indigenous Shawi in the Amazon. PLoS One 2018; 13: e0205714.

8 Marengo JA, Souza CM Jr, Thonicke K, et al. Changes in climate and land use over the Amazon region: current and future variability and trends. Front Earth Sci 2018: 6: 228

9 Harper SL, Berrang-Ford L, Carcamo C, et al. The Indigenous climate-food-health nexus. In: Mason LR, Rigg J, eds. People and climate change: vulnerability, adaptation, and social justice. Oxford: Oxford Scholarship Online, 2019: 184.

10 Chang'a LB, Kijazi AL, Mafuru KB, et al. Assessment of the evolution and socio-economic impacts of extreme rainfall events in October 2019 over the east Africa. Atmos Clim Sci 2020; 10: 319-38. 